\title{
BMJ Open Prevalence and factors associated with depression, anxiety and stress among healthcare workers of Trinidad and Tobago during COVID-19 pandemic: a cross-sectional study
}

\author{
B Shivananda Nayak (D) , ${ }^{1}$ Pradeep Kumar Sahu, ${ }^{2}$ Koomatie Ramsaroop, ${ }^{3}$ \\ Shivanand Maharaj, ${ }^{4}$ William Mootoo, ${ }^{4}$ Sharaz Khan, ${ }^{5}$ Rian Marie Extavour ${ }^{6}$
}

To cite: Nayak BS, Sahu PK, Ramsaroop K, et al. Prevalence and factors associated with depression, anxiety and stress among healthcare workers of Trinidad and Tobago during COVID-19 pandemic: a crosssectional study. BMJ Open 2021;11:e044397. doi:10.1136/ bmjopen-2020-044397

- Prepublication history for this paper is available online. To view these files, please visit the journal online (http://dx.doi. org/10.1136/bmjopen-2020044397).

Received 02 September 2020 Revised 22 March 2021 Accepted 23 March 2021

\section{ABSTRACT}

Objectives To determine the prevalence and factors associated with depression, anxiety and stress among healthcare workers (HCWs) during COVID-19 pandemic. Design Cross-sectional online survey.

Setting HCWs from four major hospitals within the Regional Health Authorities of Trinidad and Tobago.

Participants 395 HCWs aged $\geq 18$ years.

Main outcome measures Depression, anxiety and stress scores.

Results Among the $395 \mathrm{HCWs}, 42.28 \%, 56.2 \%$ and $17.97 \%$ were found to have depression, anxiety and stress, respectively. In the final stepwise regression model, contact with patients with confirmed COVID-19, $p<0.001$ (95\% Cl 3.072 to 6.781) was reported as significant predictors of depression. Further, gender, $p<0.001$ (95\% $\mathrm{Cl} 2.152$ to 5.427$)$ and marital status, $p<0.001$ (95\% Cl 1.322 to 4.270) of the HCWs were considered to be correlated with anxiety. HCWs who had contact with patients with suspected COVID-19 had lower depression, $p<0.001(95 \% \mathrm{Cl}-5.233$ to -1.692$)$ and stress, $p<0.001$ (95\% Cl -5.364 to -1.591$)$.

Conclusions This study has depicted the prevalence and evidence of depression, anxiety and stress among HCWs during the COVID-19 pandemic. The findings of the study will serve as supportive evidence for the timely implementation of further planning of preventative mental health services by the Ministry of Health, for frontline workers within the public and private health sectors.

\section{INTRODUCTION}

The COVID-19 pandemic has resulted in dramatic challenges to healthcare systems worldwide. There has been an increased awareness to protect frontline workers from COVID-19 exposure and its consequences ${ }^{1}$ which has inevitably led health administrators to embrace new paradigms of healthcare. There is emerging evidence that coping with the rapidly changing recommendations and the new norms of the healthcare system can affect not only the physical, but
Strengths and limitations of this study

- This is a novel study conducted in Trinidad and Tobago which describes the prevalence and factors associated with depression, anxiety and stress among healthcare workers (HCWs) during this COVID-19 pandemic.

- The findings showed the need for continued assessment of the psychological impact of the COVID-19 pandemic on frontline HCWs in Trinidad and Tobago, who are vital for the proper functioning of health institutions.

- The study is reproducible and feasible which can be used in different regions of the world as a means of identifying the psychological well-being and the impact of the unprecedented pandemic on its HCWs.

- This study did not control for factors that may have influenced anxiety, depression or stress scores such as pre-existing depression or anxiety before the pandemic, work setting/amenities of HCWs and differences from level of qualifications.

The cross-sectional design of the study limits our ability to make causal inferences.

also the psychological well-being, of healthcare workers (HCWs) during the COVID-19 pandemic. Acute stress involves adaptive physiological responses to meet anticipated increase demand ${ }^{2}$ otherwise deleterious effects on psychological functioning can occur. $^{23}$

Among HCWs, depressive symptoms and anxiety were increased compared with norms. ${ }^{45}$ Studies emphasise the need for early detection of the clinical mood symptoms and subthreshold syndromes before they evolve to more complex responses. Meta-analyses have recorded pooled prevalence rates of anxiety and depression among HCWs during COVID-19 to be $23.2 \%$ and $22.8 \%$, respectively. ${ }^{6-8}$ In Hong Kong, medical and nursing 
staff were found to be vulnerable to mental exhaustion and anxiety. ${ }^{9}$ German doctors reported high levels of anxiety and depressive symptoms. ${ }^{10}$ In China, more than $70 \%$ of HCWs during this pandemic reported psychological distress including insomnia, anxiety and depression. ${ }^{11}$

To date, the impact of COVID-19 on the psychological well-being of medical HCWs in Trinidad and Tobago is yet to be established. The Ministry of Health of Trinidad and Tobago has identified HCWs caring for patients with COVID-19 to be at risk of the disease and has provided local guidelines for precaution and use of personal protective equipment, health education and health promotion on COVID-19 for all staff. ${ }^{12}$ Effective 30 June 2020, there were 5061 samples submitted for testing, 130 positive COVID-19 cases, with 8 deaths. ${ }^{12}$ A parallel healthcare system with structured logistics was established in Trinidad to care for positive and suspected COVID-19 cases. The hospital staff has experienced an extreme reshuffling with new departmental protocols which can impact on the HCWs' psychological well-being.

Our analysis which included the 21-item Depression, Anxiety and Stress Scale (DASS-21) aimed to provide valuable insight of potential vulnerabilities of HCWs with respect to depression, anxiety and stress levels. Our study is thought to be valuable in helping to identify the psychological effects of the COVID-19 pandemic on HCWs and to determine if a proactive holistic approach to their well-being is needed. These should include mechanisms to provide additional mental health interventions, address broader aspects of wellness and greater staff social support. These are all important in an effort to enhance psychological resilience among HCWs and should be considered if we are to ensure a robust clinical workforce. Hence, the aim of our study was to determine the prevalence of depression, anxiety and stress symptoms among HCWs during COVID-19 pandemic in Trinidad and Tobago. Further, the study aimed to identify the demographic and others factors which can be predictive of levels of depression, anxiety and stress.

\section{METHODS}

\section{Study design and settings}

A cross-sectional study was conducted from 11 May 2020 to 30 June 2020. There are four regional health authorities (RHAs) which operate health facilities in Trinidad which include the: North Central Regional Health Authority, North West Regional Health Authority, Eastern Regional Health Authority and South West Regional Health Authority. The current estimated HCWs in the country is more than 9500 (68 per 10000 habitants). ${ }^{13}$ Convenience sampling method was used to obtain HCWs from four major hospitals, each one from the four RHAs. The HCWs were those employed in various clinical departments and were physicians, nurses, laboratory workers, pharmacists and others (radiographers, dentists, physiotherapists and medical social workers). The Google form link of the questionnaire was successfully sent to the HCWs via emails. We sent emails to a minimum of $516 \mathrm{HCWs}$ from these four hospitals using their personal emails which were obtained from the relevant departments, since the COVID-19 pandemic created challenges and restrictions for approaching HCWs physically. The questionnaire link was also sent via WhatsApp using a snowball spreading technique within the department starting from the researchers' acquaintances.

\section{Study participants and sample size}

We included HCWs over 18 years of age who agreed to participate in the online survey. HCWs who were quarantined or on leave or unable to participate due to physical or emotional distress were excluded. The purpose of the study was explained in the written form attached to the questionnaire. To minimise the possibility of nonresponse bias, we sent three email reminders to the HCWs from the selected hospitals. To determine the adequacy of the sample, we used the formula $n=\left(Z_{1-\alpha}\right)^{2} \times(P(1-P) /$ $\left.\mathrm{D}^{2}\right)$, where $Z_{1-\alpha}=Z_{0.95}=1.96, P$ is the proportion of depression, anxiety, and stress among population (we assumed that depression, anxiety and stress would be present in $50 \%$ of the population) and $\mathrm{D}$ is the margin of error $(0.05) .{ }^{14}$ Based on the formula, a minimum of 384 participants would be required to obtain precise estimates of population value.

\section{Patient and public involvement}

No patients or members of the public were involved in this study.

\section{Study instruments}

The questionnaire consisted of two sections: (1) demographic and occupational characteristics of the HCWs, and (2) the shorter version of the validated DASS-21. Demographic data included gender, occupation (physicians, nurses, lab workers, pharmacists and others), age, nationality, marital status, work experience, average duty hours per week, sleep duration, contact with patients with suspected COVID-19, contact with patients with confirmed COVID-19 and direct contact with COVID-19 lab specimen. In the occupation variable, the term 'others' included radiographers, dentists, physiotherapists and medical social workers. We defined short sleep duration as a self-reported average less than 7 hours of sleep per day, based on the National Sleep Foundation's recommendation that adults should sleep 7-9hours/ day. ${ }^{15}$

The DASS-21 version was administered to measure the depression, anxiety and stress among HCWs. It is a psychological screening instrument capable of measuring negative emotional states of depression, anxiety and stress. ${ }^{16}$ The depression subscale assesses hopelessness, self-deprecation, devaluation of life and lack of interest. The anxiety subscale assesses autonomic arousal, skeletal muscle effect and subjective experience of anxious effect. The stress subscale assesses relaxing difficulty, nervous arousal, and being easily agitated, impatient and 
over-reactive. ${ }^{17}$ The DASS-21 has demonstrated adequate reliability (ranging from 0.81 to 0.97 ) and construct validity. ${ }^{18} 19$ Each of the three domains comprises seven items scored on a Likert scale from 0 to 3 (0: did not apply to me at all, 1: applied to me to some degree, 2: applied to me to a considerable degree, 3 : applied to me very much). The final score for each subscale was multiplied by 2 and used to evaluate the negative emotional status. Respondents' scores ranging from 0 to 9 for depression, $0-7$ for anxiety and 0-14 for stress represented the normal category. Higher scores indicated higher depression, anxiety or stress, which ranged from mild to extremely severe disorder. Mild scores ranged 10-13 for depression, 8-9 for anxiety and 15-18 for stress. Moderate scores were: 14-20 for depression, 10-14 for anxiety and 19-25 for stress. Severe scores 21-27 for depression, 15-19 for anxiety and 26-33 for stress. Scores above 27 for depression, above 19 for anxiety and above 33 for stress were considered extremely severe. The DASS-21 severity categories were used to characterise the full range of scores in the population. For instance, 'mild' indicated that the person is above the population mean but still well below the typical severity where intervention is sought, rather than a diagnosis of the disorder level.

\section{Data analysis}

Data analyses were carried out using SPSS V.24. Descriptive analyses were performed on the demographic and occupation-related variables. To check the internal consistency of the DASS-21, Cronbach's $\alpha$ was used. Student's t-tests were used to assess the differences in depression, anxiety and stress level of the HCWs according to gender, sleep duration, contact with patients with suspected COVID-19, contact with patients with confirmed COVID-19 and direct contact with COVID-19 lab specimen. In addition, one-way analysis of variance (ANOVA) and the Bonferroni post hoc test were performed to make comparisons of depression, anxiety and stress according to the variables with more than two groups such as profession, age, nationality, marital status, work experience and average duty hours per week. A p value less than or equal to 0.05 was set as the threshold for statistical significance for both the t-test and the ANOVA. Further, stepwise regression analyses were used to explore the independent relationships of non-modifiable factors on outcome variables. Variables with a $\mathrm{p}$ value greater than 0.05 were excluded from stepwise regression model.

\section{RESULTS}

\section{Demographic characteristics}

In total, 413 responses were received, of which 18 questionnaires were incomplete, enabling 395 responses to be eligible for further analysis. Of the total 395 HCWs, 268 $(67.8 \%)$ were female, $208(52.7 \%)$ were physicians and $168(42.5 \%)$ were aged 30 years and below. The majority of the respondents $(89.4 \%)$ were of a Trinidad and Tobago nationality, and more than half (54.4\%) of them were single. The majority of the respondents $(70.9 \%)$ had 1-10 years' work experience and most of them $(71.1 \%)$ worked an average of 50 hours or less per week. Most of the respondents $(81.3 \%)$ reported sleep duration of less than 7 hours. During the study period, $225(57 \%)$ participants agreed that they had contact with the patients with suspected COVID-19 and $82(20.8 \%)$ had contact with patients with confirmed COVID-19. Also 145 (65.7\%) participants had direct contact with COVID-19 lab specimen (table 1). In the present study, Cronbach's $\alpha$ coefficient for DASS-21 (depression, anxiety and stress) ranged from 0.78 to 0.89 . Of the $395 \mathrm{HCWs}, 42.28 \%$ exhibited mild to extremely severe depression symptoms; $56.2 \%$ reported mild to extremely severe anxiety symptoms and $17.97 \%$ perceived mild to extremely severe stress symptoms (figure 1).

\section{Comparative analysis of depression, anxiety and stress}

In the comparative analysis of depression with the demographic characteristics of HCWs (table 2), significant associations were observed between depression and age $(p<0.05)$. Post hoc tests revealed that HCWs of 30 years and younger exhibited higher depression in comparison with the age group of 31-40, 41-50 and above 50 years $(\mathrm{p}<0.05)$. There was a significant association between depression and marital status $(\mathrm{p}<0.05)$. Post hoc tests showed that HCWs who were single had higher depression score in comparison with those who were married $(p<0.05)$. There was a significant association between depression and work experience $(\mathrm{p}<0.05)$. Post hoc tests revealed that HCWs with 1-10 years' work experience had higher depression score than those with 11-20 years' work experience. In addition, HCWs who had contact with the patients with suspected COVID-19 exhibited higher depression score in comparison with those without contact $(\mathrm{p}<0.05)$.

Regarding the anxiety level of the HCWs (table 2), women were more anxious than their male counterparts $(\mathrm{p}<0.05)$. Significant associations were recorded between anxiety and professions $(\mathrm{p}<0.05)$. Post hoc tests revealed that physicians had higher levels of anxiety than lab workers and nurses $(p<0.05)$. A significant association between anxiety and age was found $(p<0.05)$. Post hoc tests revealed that HCWs aged 30 years and younger exhibited higher anxiety in comparison with HCWs aged $31-40,41-50$ and above 50 years $(\mathrm{p}<0.05)$. A significant association between anxiety and marital status was found $(\mathrm{p}<0.05)$. Post hoc tests showed that HCWs who were single had higher anxiety scores in comparison with those who were married $(p<0.05)$. Similarly, a significant association between anxiety and work experience was found $(p<0.05)$. Post hoc tests revealed that HCWs with the work experience of 1-10 years had higher anxiety score than those with work experience of $11-20$ years $(p<0.05)$. In addition, HCWs who slept less than 7 hours had higher anxiety score than those whose sleep duration was more than 7 hours $(\mathrm{p}<0.05)$. Higher anxiety scores were seen in HCWs who had contact with the patients with suspected 
Table 1 Demographic information of participants $(n=395)$

\begin{tabular}{lll}
\hline Participants' characteristics & Frequency & Percentage \\
\hline Gender & & \\
Male & 127 & 32.2 \\
Female & 268 & 67.8
\end{tabular}

Profession

\begin{tabular}{|lrr|}
\hline Physicians & 208 & 52.7 \\
\hline Nurses & 31 & 7.8 \\
\hline Lab workers & 68 & 17.2 \\
\hline Pharmacists & 29 & 7.3 \\
\hline Others & 59 & 14.9 \\
\hline
\end{tabular}

Age

\begin{tabular}{|c|c|c|}
\hline Below 30 & 168 & 42.5 \\
\hline $31-40$ & 148 & 37.7 \\
\hline $41-50$ & 58 & 14.7 \\
\hline Above 50 & 21 & 5.3 \\
\hline \multicolumn{3}{|l|}{ Nationality } \\
\hline Trinbagonian & 353 & 89.4 \\
\hline CARICOM & 21 & 5.3 \\
\hline Others & 21 & 5.3 \\
\hline \multicolumn{3}{|l|}{ Marital status } \\
\hline Married & 164 & 41.5 \\
\hline Single & 215 & 54.4 \\
\hline Common law & 16 & 4.1 \\
\hline \multicolumn{3}{|l|}{ Work experience } \\
\hline $1-10$ years & 280 & 70.9 \\
\hline $11-20$ years & 83 & 21 \\
\hline Above 20 years & 32 & 8.1 \\
\hline \multicolumn{3}{|c|}{ Average duty hours per week } \\
\hline Below 50 & 281 & 71.1 \\
\hline $51-70$ & 77 & 19.5 \\
\hline Above 70 & 37 & 9.3 \\
\hline \multicolumn{3}{|l|}{ Sleep duration } \\
\hline Below 7 hours & 321 & 81.3 \\
\hline 7 hours and above & 74 & 18.7 \\
\hline \multicolumn{3}{|c|}{ Contact with patients with suspected COVID-19 } \\
\hline Yes & 225 & 57 \\
\hline No & 170 & 43 \\
\hline \multicolumn{3}{|c|}{$\begin{array}{l}\text { Contact with patients with } \\
\text { confirmed COVID-19 }\end{array}$} \\
\hline Yes & 82 & 20.8 \\
\hline No & 313 & 79.2 \\
\hline
\end{tabular}

Direct contact with COVID-19

lab specimen

\begin{tabular}{lll} 
Yes & 145 & 36.7 \\
No & 250 & 63.3 \\
\hline
\end{tabular}

CARICOM, Caribbean community; HCWs, healthcare workers.
COVID-19 in comparison with those without such contact $(\mathrm{p}<0.05)$.

A significant difference was found between male and female HCWs with regard to their stress scores $(p<0.05$, table 2). Stress and age were significantly correlated $(p<0.05)$. Post hoc tests indicated that HCWs of 30 years and younger exhibited higher stress scores in comparison with other HCWs (31-40, 41-50 and above 50 years, $\mathrm{p}<0.05)$. In addition, a significant association between stress and marital status was found $(\mathrm{p}<0.05)$. Post hoc tests showed that HCWs who were single had higher stress score relative to those who were married $(p<0.05)$. Further, HCWs who had contact with the patients with suspected COVID-19 exhibited higher anxiety score in comparison with those without such contact $(\mathrm{p}<0.05)$.

Stepwise regression analysis was performed considering depression, anxiety and stress as dependent variables with the independent variables such as gender, marital status, contact with patients with suspected COVID-19 and contact with patients with confirmed COVID-19 (table 3). The variables for stepwise regression were selected based on significant correlations $(\mathrm{p}<0.05)$ using Pearson product moment. Contact with patients with confirmed COVID-19, $\mathrm{p}<0.001$ (95\% CI 3.072 to 6.781 ) was reported as significant predictors of depression. Gender, $\mathrm{p}<0.001$ (95\% CI 2.152 to 5.427$)$ and marital status, $\mathrm{p}<0.001$ (95\% CI 1.322 to 4.270 ) of the HCWs were considered to be correlated with the anxiety. Respondents who reported contact with patients with suspected COVID-19 had lower depression, $\mathrm{p}<0.001$ (95\% CI -5.233 to -1.692$)$ and stress, $\mathrm{p}<0.001(95 \%$ CI -5.364 to -1.591$)$.

\section{DISCUSSION}

The present study aimed to determine the prevalence and factors associated with depression, anxiety and stress among HCWs during COVID-19 pandemic in Trinidad and Tobago. To our knowledge, this study is among the first to report the psychological aspects of mental health in HCWs of Trinidad and Tobago during COVID-19 pandemic. We found a high prevalence of depression, anxiety and stress among HCWs in Trinidad and Tobago. The relentless spread of the virus, the lack of sufficient rest, the threat of infection, the workload and frequent isolation from family are all factors that can contribute to the high risk of acute mental health conditions in HCWs when other studies were reviewed. ${ }^{20}$

Among the HCWs, the highest prevalence $(56.2 \%)$ was from anxiety and is comparable with other international studies. Previous studies showed the COVID-19 pandemic proved to cause significant psychological impact on HCWs. ${ }^{21}$ In a review study, Preti $e t a l^{22}$ reported that the prevalence of depressive symptom was between $27.5 \%$ and $50.7 \%$ in HCWs generally but with higher rates during the COVID-19 pandemic $(50.4 \%-50.7 \%)$ in this same population. The prevalence of anxiety among HCWs during the pandemic was variable in different populations. In a study in China, the prevalence of anxiety among HCWs 


\section{Prevalence of depression, anxiety and stress among HCWs}

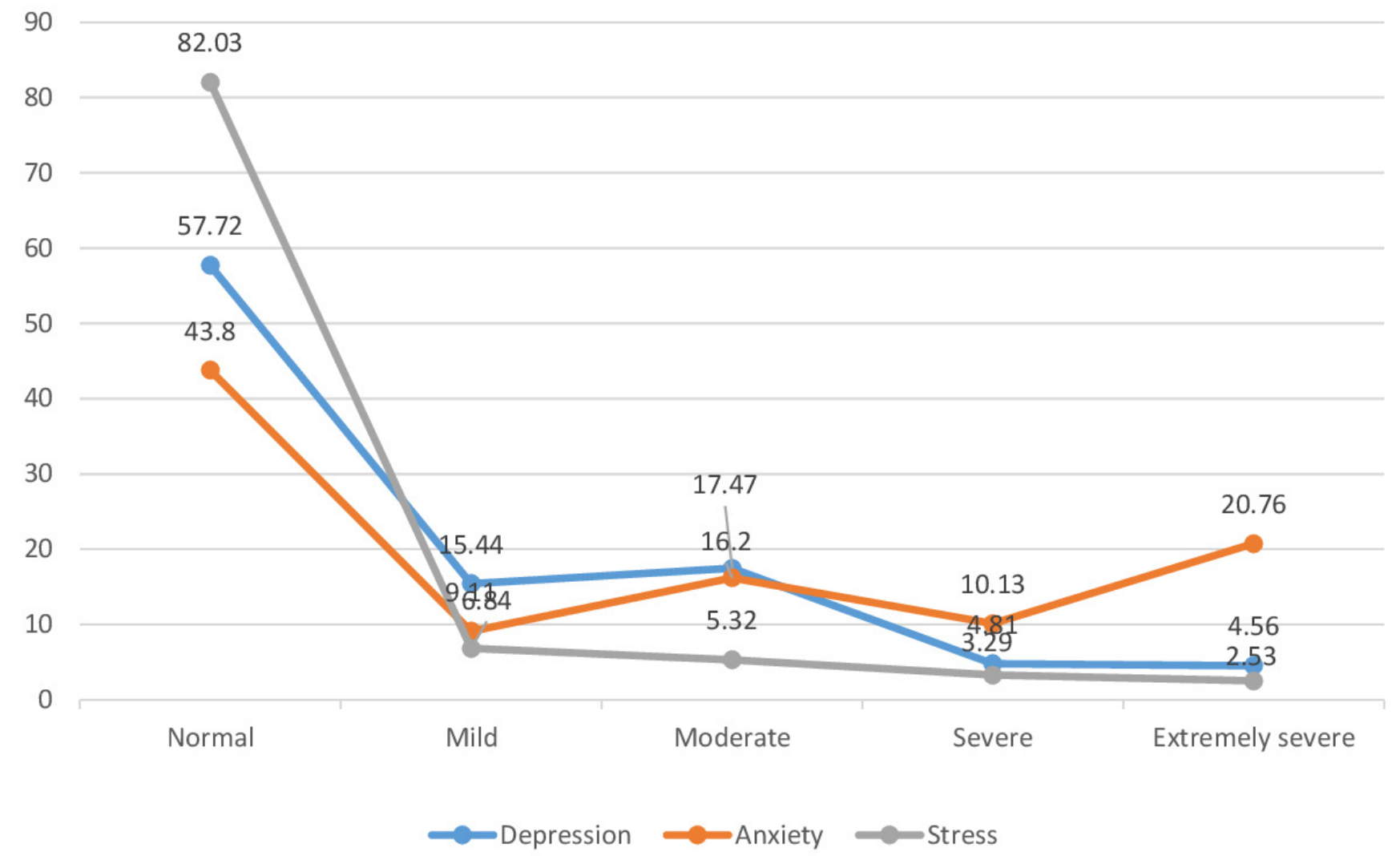

Figure 1 Prevalence of depression, anxiety and stress among HCWs. HCWs, healthcare workers.

$(54.2 \%)$ was similar to our findings ${ }^{23}$ but was reported lower $(44.7 \%)$ in others. ${ }^{24}$ The stress level reported in our study was much lower than the studies conducted in China $^{25}$ and Saudi Arabia. ${ }^{21}$

The study did not control for factors that may have influenced anxiety, depression or stress scores, such as preexisting depression or anxiety, comorbidities, work setting (primary/secondary health services), sector (public/ private), workload, level of qualifications (undergraduate/postgraduate), personal or organisational support systems, and standardised protocols. As this study was only done during the pandemic, and not before, it would be difficult to say if these psychological factors are due to the pandemic or pre-existing. There may have been statistical correlations between age and work experience, and between exposure to suspected cases and exposure to confirmed cases, which may have affected the regression models. Another limitation of the study was that there may have been non-response bias since very busy HCWs may not have completed the survey and we were also unable to calculate the response rate of the HCWs. These HCWs may have been those with high levels of anxiety, stress and depression resulting in possible underestimates of the true prevalence. We were also limited in identifying participants with high scores on the DASS-21 who could have opted to be contacted. Identification of participants is not possible because the collection of data was anonymous, which is also the criteria of the different ethical committees from where approval was obtained. However, the Health Authority would consider the results of our study for remedial measures.

In the final stepwise regression model, HCWs' contact with patients with confirmed COVID-19 and contact with patients with suspected COVID-19 were significantly associated with depression. In addition, gender and marital status were considered to be correlated with anxiety, while the factor significantly associated with stress was contact with patients with suspected COVID-19. Our findings are consistent with the previous studies where it was found that direct contact with a patient with suspected or confirmed COVID-19 was the major risk factor which caused stress and anxiety among the HCWs. ${ }^{23} 26$ In a cross-sectional study in China, frontline HCWs engaged in direct diagnosis, treatment and care of patients with COVID-19 were associated with a higher risk of symptoms of depression, anxiety, distress and insomnia. ${ }^{27}$

In recent studies on HCWs during COVID-19 pandemic, it was found that women were more susceptible to depression, anxiety and stress during the pandemic. ${ }^{1125}$ Similar findings have been reported in a study in Oman. ${ }^{27}$ In an analysis of an Indian study during the COVID-19 pandemic, the risk factors for depression, 
Table 2 Comparative analysis of depression, anxiety and stress based on sociodemographic characteristics ( $\mathrm{n}=395)$

\begin{tabular}{|c|c|c|c|c|c|c|}
\hline \multirow{2}{*}{ Characteristics } & \multicolumn{2}{|l|}{ Depression } & \multicolumn{2}{|l|}{ Anxiety } & \multicolumn{2}{|l|}{ Stress } \\
\hline & Mean (SD) & $P$ value & Mean (SD) & $P$ value & Mean (SD) & $P$ value \\
\hline \multicolumn{7}{|l|}{ Gender } \\
\hline Male & $7.98(8.08)$ & 0.065 & 8.84 (10.02) & $0.002^{*}$ & $5.51(8.60)$ & $0.006^{*}$ \\
\hline Female & $9.63(8.32)$ & & $11.82(9.92)$ & & $8.14(8.90)$ & \\
\hline \multicolumn{7}{|l|}{ Profession } \\
\hline Physicians & $10.07(8.30)$ & 0.097 & $11.90(10.29)$ & $0.044^{*}$ & $7.99(9.26)$ & 0.138 \\
\hline Nurses & 7.48 (7.39) & & $7.81(8.89)$ & & $5.29(6.34)$ & \\
\hline Lab workers & $7.32(7.88)$ & & 8.59 (8.96) & & $5.26(8.17)$ & \\
\hline Pharmacists & 9.66 (7.78) & & $12.48(9.60)$ & & 8.34 (9.67) & \\
\hline Others & 8.31 (8.95) & & 9.97 (10.68) & & $7.73(8.80)$ & \\
\hline \multicolumn{7}{|l|}{ Age } \\
\hline 30 and below & $10.88(8.75)$ & $<0.001^{*}$ & $13.21(11.15)$ & $<0.001^{*}$ & $8.94(9.86)$ & $0.014^{*}$ \\
\hline $31-40$ & 8.69 (8.01) & & $9.81(8.92)$ & & 6.35 (7.89) & \\
\hline $41-50$ & $6.31(6.83)$ & & $7.86(8.86)$ & & $5.82(7.99)$ & \\
\hline Above 50 & $5.43(6.17)$ & & $5.90(6.43)$ & & 4.86 (7.68) & \\
\hline \multicolumn{7}{|l|}{ Nationality } \\
\hline Trinbagonian & $9.36(8.27)$ & 0.188 & 11.14 (10.15) & 0.093 & 7.58 (8.97) & 0.193 \\
\hline CARICOM & 7.14 (7.68) & & $7.71(9.10)$ & & $4.76(8.54)$ & \\
\hline Others & 6.67 (8.54) & & $7.43(8.65)$ & & $5.14(7.09)$ & \\
\hline \multicolumn{7}{|l|}{ Marital status } \\
\hline Married & 7.15 (7.65) & $<0.001^{*}$ & $8.29(8.50)$ & $<0.001^{\star}$ & $5.17(7.45)$ & $<0.001^{*}$ \\
\hline Single & $10.64(8.41)$ & & $12.70(10.73)$ & & $8.80(9.45)$ & \\
\hline Common law & 8.38 (8.68) & & $10.13(10.42)$ & & $8.88(10.46)$ & \\
\hline \multicolumn{7}{|l|}{ Work experience } \\
\hline $1-10$ years & $10.00(8.48)$ & $0.003^{*}$ & 11.75 (10.41) & $0.009^{*}$ & 7.97 (9.07) & 0.057 \\
\hline $11-20$ years & $6.84(7.05)$ & & $8.60(8.76)$ & & $5.45(7.84)$ & \\
\hline Above 20 years & $7.06(8.10)$ & & $7.06(8.10)$ & & $6.19(9.18)$ & \\
\hline \multicolumn{7}{|c|}{ Average duty hours per week } \\
\hline Below 50 & $8.72(8.11)$ & 0.317 & $10.09(9.61)$ & 0.093 & $6.95(8.60)$ & 0.486 \\
\hline $51-70$ & $9.77(8.12)$ & & $12.83(10.24)$ & & $8.13(9.12)$ & \\
\hline Above 70 & $10.59(9.62)$ & & $11.57(10.06)$ & & $8.16(10.43)$ & \\
\hline \multicolumn{7}{|l|}{ Sleep duration } \\
\hline Below 7 hours & $9.45(8.47)$ & 0.077 & $11.44(10.02)$ & $0.005^{\star}$ & $7.71(9.07)$ & 0.055 \\
\hline 7 hours and above & $7.57(7.19)$ & & $7.84(9.76)$ & & $5.51(7.79)$ & \\
\hline \multicolumn{7}{|c|}{ Contact with patients with suspected COVID-19 } \\
\hline Yes & $10.35(7.45)$ & $0.001^{*}$ & $12.12(10.06)$ & $0.002^{*}$ & $8.36(9.21)$ & $0.006^{*}$ \\
\hline No & $7.45(7.72)$ & & $8.96(9.80)$ & & $5.89(8.24)$ & \\
\hline \multicolumn{7}{|c|}{ Contact with patients with confirmed COVID-19 } \\
\hline Yes & $7.98(7.14)$ & 0.167 & $10.10(8.84)$ & 0.501 & $6.34(7.32)$ & 0.275 \\
\hline No & $9.39(8.53)$ & & $10.94(10.36)$ & & $7.55(9.24)$ & \\
\hline \multicolumn{7}{|c|}{ Direct contact with COVID-19 lab specimen } \\
\hline Yes & $8.98(8.50)$ & 0.827 & $11.09(9.76)$ & 0.625 & $7.12(8.88)$ & 0.761 \\
\hline No & 9.17 (8.15) & & $10.58(10.24)$ & & 7.40 (8.89) & \\
\hline
\end{tabular}

*Significant at 0.05 level.

CARICOM, Caribbean community. 
Table 3 Summary of stepwise regression analysis for variables predicting depression, anxiety and stress

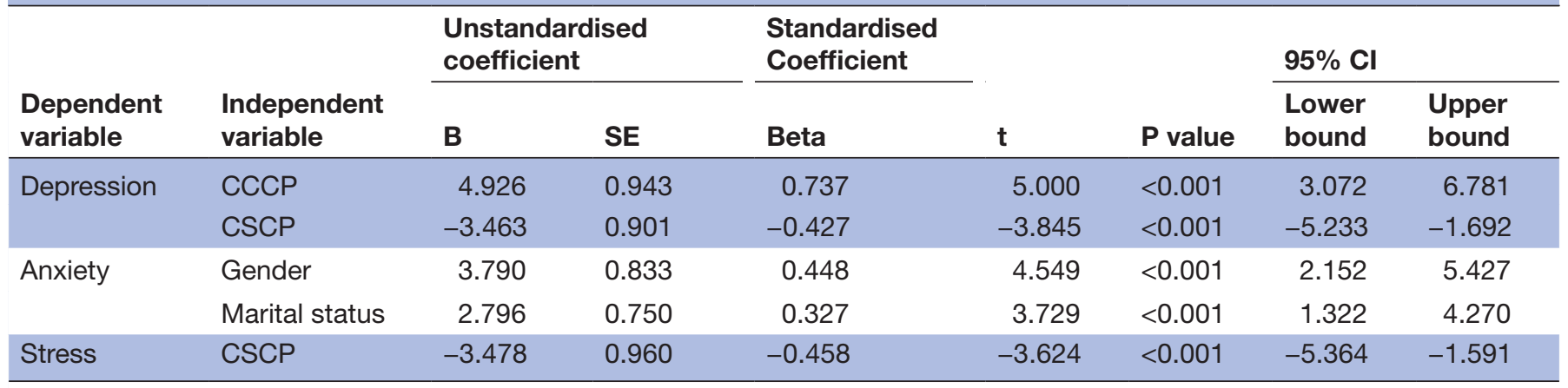

B, unstandardised beta; CCCP, contact with confirmed COVID-19 patients; CSCP, contact with suspected COVID-19 patients.

anxiety and stress symptoms revealed that female gender was a significant factor. ${ }^{28}$ Evidence from previous studies has shown the positive effect of social support on the mental health of the HCWs. ${ }^{29}{ }^{30}$ Furthermore, it is well known that women are more vulnerable to developing depressive symptoms and that adequate social support provided by partners or spouses represents a protective factor for the psychological well-being. ${ }^{31}$ In our study, we found that marital status was significantly related to the psychological impact. Marriage and family support can effectively alleviate the mental status of the HCWs. The negative psychological impact on single HCWs may be a result of the lack of personal committed relationships to assist with coping with the daily challenges of the work environment and the risk of contracting COVID-19. Our findings were contradictory with one review study where the authors did not find strong evidence suggesting that personal factors make the difference in the maladaptive psychological responses reported by HCWs. ${ }^{22}$

The contributory demographic and associated occupational factors cannot be ignored. They warrant the need for continued assessment of the psychological well-being of our HCWs during this unprecedented pandemic to be done anonymously. It is important to strengthen the psychological well-being of our frontline HCWs, who are a vital resource to the quality of the medical services provided during this pandemic. ${ }^{23}$ This evidence highlights the importance of developing support systems and strategies via country-guided policies governing the health institutions to mitigate this observation. Local health institutions had already implemented activities to notify, share and educate HCWs though workshops, lectures, seminars and electronic broadcasting. This enabled HCWs to be better prepared for the challenges by learning from the other parts of the world that were affected by the pandemic before the first case of COVID-19 manifested in Trinidad and Tobago on 12 March 2020.

We have identified HCWs with potentially new or underlying psychological stressors, and intervention may be beneficial. It is recommended that new survey technology to identify the high-risk workers and mechanisms to address broader aspects of wellness with greater staff social support by the Ministry of Health is required.
This will help identify the workers who may benefit from medical guidance, as part of our commitment to the continuum of healthcare. One strategy can provide counselling services and outreach gatherings or workshops at each of the regional hospitals which will be made readily available so that staff can access them anonymously. Psychological treatment such as cognitive-behavioural therapy and mindfulness therapy could be helpful. ${ }^{32}$ Currently, a staff clinic is set up at one location with access to psychological counselling on a 24-hour basis. However, there is justification for more of this kind with additive supportive systems for HCWs and by extension of their families.

\section{CONCLUSION}

This study found high levels of anxiety, stress and depression, respectively, among HCWs who responded. The main observation was evident particularly among the single, female HCWs and those in contact with patients with either confirmed or suspected COVID-19. It supports the need for further planning for the effective psychological well-being of HCWs which has also been echoed in other similar studies. The implication of the strategies within the health institutions will ultimately mitigate some psychological issues among frontline HCWs who are essential for the sustainment and effectiveness of the healthcare systems in our country. These strategies may be developed to target HCWs who are female, single and all HCWs who are in contact with patients with suspected COVID-19 during their routine practice.

\section{Author affiliations}

${ }^{1}$ Faculty of Medical Sciences, Department of Preclinical Sciences, The University of the West Indies at St Augustine, St Augustine, Trinidad and Tobago

${ }^{2}$ Centre for Medical Sciences Education, The University of the West Indies, St Augustine Campus, St Augustine, Trinidad and Tobago

${ }^{3}$ Department of Adult Medicine, North Central Regional Health Authority, Port of Spain, Trinidad and Tobago

${ }^{4}$ Department of Surgery, Port of Spain General Hospital, Port of Spain, Trinidad and Tobago

${ }^{5}$ Department of Accident and Emergency, San Fernando General Hospital, Port of Spain, Trinidad and Tobago

${ }^{6}$ School of Pharmacy, Faculty of Medical Sciences, The University of the West Indies at Saint Augustine, Port of Spain, Trinidad and Tobago 
Correction notice This article has been corrected since it was published. Surname of author Rian Marie Extavour has been corrected.

Acknowledgements The authors would like to thank the Ministry of Health for giving the approval to conduct this study.

Contributors BSN planned the study, conducted the online survey and wrote the article. PKS prepared the questionnaire, performed statistical analysis and wrote the article. KR conducted the online survey and wrote the article. SM prepared and conducted the online survey. WM and SK conducted the online survey. RME wrote part of the discussion and conducted the online survey. All the authors contributed to the final version of the article to be published.

Funding The authors have not declared a specific grant for this research from any funding agency in the public, commercial or not-for-profit sectors.

Competing interests None declared.

Patient consent for publication Not required.

Ethics approval The study was approved by the Campus Ethics Committee, The University of the West Indies (CREC-SA.0380/05/2020), Ministry of Health, Trinidad and Tobago (3/13/441 Vol. II) and Public Health Observatory, North Central Regional Health Authority, Trinidad. All participants provided informed consent electronically prior to registration. The informed consent page presented two options (yes/no). Only participants who chose yes were directed to the questionnaire page, and participants could exit the survey at any time. No identifiable data were collected as part of the survey as to maintain staff confidentiality and to enhance the response rate.

Provenance and peer review Not commissioned; externally peer reviewed.

Data availability statement Data are available upon reasonable request. All data are deidentified and included in the article.

Open access This is an open access article distributed in accordance with the Creative Commons Attribution Non Commercial (CC BY-NC 4.0) license, which permits others to distribute, remix, adapt, build upon this work non-commercially, and license their derivative works on different terms, provided the original work is properly cited, appropriate credit is given, any changes made indicated, and the use is non-commercial. See: http://creativecommons.org/licenses/by-nc/4.0/.

ORCID iD

B Shivananda Nayak http://orcid.org/0000-0001-5928-3779

\section{REFERENCES}

1 Adams JG, Walls RM. Supporting the health care workforce during the COVID-19 global epidemic. JAMA 2020;323:1439-40.

2 Charney DS. Psychobiological mechanisms of resilience and vulnerability: implications for successful adaptation to extreme stress. Am J Psychiatry 2004;161:195-216.

3 Lapa TA, Madeira FM, Viana JS, et al. Burnout syndrome and wellbeing in anesthesiologists: the importance of emotion regulation strategies. Minerva Anestesiol 2017;83:191-9.

4 Chen Y, Zhou H, Zhou Y, et al. Prevalence of self-reported depression and anxiety among pediatric medical staff members during the COVID-19 outbreak in Guiyang, China. Psychiatry Res 2020;288:113005.

5 Mo Y, Deng L, Zhang L, et al. Work stress among Chinese nurses to support Wuhan in fighting against COVID-19 epidemic. J Nurs Manag 2020;28:1002-9.

6 Wang C, Pan R, Wan X, et al. A longitudinal study on the mental health of general population during the COVID-19 epidemic in China. Brain Behav Immun 2020;87:40-8.

7 Gao J, Zheng P, Jia Y, et al. Mental health problems and social media exposure during COVID-19 outbreak. PLoS One 2020;15:e0231924.

8 Wang $\mathrm{C}$, Pan R, Wan X, et al. Immediate psychological responses and associated factors during the initial stage of the 2019 coronavirus disease (COVID-19) epidemic among the general population in China. Int J Environ Res Public Health;17:1729.

9 Cheung T, Fong TKH, Bressington D. COVID-19 under the SARS cloud: mental health nursing during the pandemic in Hong Kong. $J$ Psychiatr Ment Health Nurs 2021;28:115-7.
10 Bohlken J, Schömig F, Lemke MR, et al. [COVID-19 Pandemic: Stress Experience of Healthcare Workers - A Short Current Review]. Psychiatr Prax 2020;47:190-7.

11 Lai J, Ma S, Wang Y, et al. Factors associated with mental health outcomes among health care workers exposed to coronavirus disease 2019. JAMA Netw Open 2020;3:e203976.

12 Ministry of Health, Government of Trinidad and Tobago. Ministry of health, government of Trinidad and Tobago, 2020. Available: https:// www.health.gov.tt

13 Pan-American Health Organization (PAHO) in collaboration with the Health Sector Human Resources Planning and Development Unit, Ministry of Health, Government of Trinidad and Tobago. Consultancy Report for the second assessment of Trinidad and Tobago's progress towards the achievement of the regional goals for human resources for health 2014.

14 Sahu P, Nayak B, Rodrigues V, et al. Prevalence of psychological distress among undergraduate medical students: a cross-sectional study. Int J App Basic Med Res 2020;10:270-5.

15 Hirshkowitz M, Whiton K, Albert SM, et al. National sleep Foundation's sleep time duration recommendations: methodology and results summary. Sleep Health 2015;1:40-3.

16 Basudan S, Binanzan N, Alhassan A. Depression, anxiety and stress in dental students. Int J Med Educ 2017;8:179-86.

17 Lovebird SH L. Manual for the depression anxiety stress scales. 2nd. Ed. Sydney: Psychology Foundation, 1995.

18 Yusoff MSB, Abdul Rahim AF, Baba AA, Fuad A, Rahim A et al. Prevalence and associated factors of stress, anxiety and depression among prospective medical students. Asian J Psychiatr 2013;6:128-33.

19 Henry JD, Crawford JR. The short-form version of the depression anxiety stress scales (DASS-21): construct validity and normative data in a large non-clinical sample. Br J Clin Psychol 2005;44:227-39.

20 Zhang W-R, Wang K, Yin L, et al. Mental health and psychosocial problems of medical health workers during the COVID-19 epidemic in China. Psychother Psychosom 2020;89:242-50.

21 Temsah M-H, Al-Sohime F, Alamro N, et al. The psychological impact of COVID-19 pandemic on health care workers in a MERS-CoV endemic country. J Infect Public Health 2020;13:877-82.

22 Preti E, Di Mattei V, Perego G, et al. The psychological impact of epidemic and pandemic outbreaks on healthcare workers: rapid review of the evidence. Curr Psychiatry Rep 2020;22:43.

23 Xiao X, Zhu X, Fu S, et al. Psychological impact of healthcare workers in China during COVID-19 pneumonia epidemic: a multi-center cross-sectional survey investigation. J Affect Disord 2020;274:405-10.

24 Zhang C, Yang L, Liu S, et al. Survey of insomnia and related social psychological factors among medical staff involved in the 2019 nove coronavirus disease outbreak. Front Psychiatry 2020;11:306.

25 Zhu Z, Xu S, Wang H, et al. COVID-19 in Wuhan: sociodemographic characteristics and hospital support measures associated with the immediate psychological impact on healthcare workers. EClinicalMedicine 2020;24:100443.

26 Liu C-Y, Yang Y-Z, Zhang X-M, et al. The prevalence and influencing factors in anxiety in medical workers fighting COVID-19 in China: a cross-sectional survey. Epidemiol Infect 2020;148:e98.

27 Badahdah A, Khamis F, Mahyijari N. The mental health of health care workers in Oman during the COVID-19 pandemic. Int J Soc Psychiatry 2020;8:20764020939596.

28 Wilson W, Raj JP, Rao S, et al. Prevalence and predictors of stress, anxiety, and depression among healthcare workers managing COVID-19 pandemic in India: a nationwide observational study. Indian J Psychol Med 2020;42:353-8.

29 Hou T, Zhang T, Cai W, et al. Social support and mental health among health care workers during coronavirus disease 2019 outbreak: a moderated mediation model. PLoS One 2020;15:e0233831.

30 Jenkins R, Elliott P, Stressors EP. Stressors, burnout and social support: nurses in acute mental health settings. J Adv Nurs 2004;48:622-31.

31 Braithwaite S, Holt-Lunstad J. Romantic relationships and mental health. Curr Opin Psychol 2017;13:120-5.

32 Ho CS, Chee CY, Ho RC, CS H, RC H. Mental health strategies to combat the psychological impact of COVID-19 beyond paranoia and panic. Ann Acad Med Singap 2020;49:155-60. 